\title{
Article choice in plural generics
}

$\begin{array}{ll}\text { Donka F. Farkas } & \text { Henriëtte de Swart } \\ \text { Department of Linguistics } & \text { Department of French } \\ \text { UCSC } & \text { Utrecht University } \\ \text { Stevenson College } & \text { Kromme Nieuwegracht } 29 \\ \text { 1156 High Street } & 3512 \text { HD Utrecht } \\ \text { Santa Cruz, CA 95064, USA } & \text { the Netherlands } \\ \text { Tel: + 1 831 459 3478 } & \text { Tel: + 31 30 2536204 } \\ \text { Fax: + } 1 \text { 831 459 3334 } & \text { Fax: + 31-30-2536167 } \\ \text { farkas@ ucsc.edu } & \underline{\text { henriette.deswart@ let.uu.nl }}\end{array}$

Corresponding author: Henriëtte de Swart

\begin{abstract}
We discuss two groups of languages where article use contrasts in generic plural sentences but is otherwise essentially similar. The languages in the first group (English and Dutch) use bare plurals in the expression of kind reference ('Dinosaurs are extinct') and in generic generalizations ('Dogs are intelligent'). The languages in the second group (French, Italian, Hungarian) use definite plurals in both cases ('Les dinosaures ont disparu', 'Les chiens sont intelligents' in French). We account for this contrast in terms of a competition between definite and indefinite forms formalized in terms of two $\mathrm{O}$ (ptimality) $\mathrm{T}$ (heoretic) syntactic constraints. The two language groups are given a uniform semantics. The contrast emerges in the interaction between the semantics of generic plural sentences and the relative weight assigned to the two constraints.
\end{abstract}


Evidence in favor of the analysis comes from the otherwise unexpected neutralization of the contrast in pseudo-generics and anaphoric generics.

Keywords: genericity, article, plural, indefinite, optimality, typology

\section{The Puzzle}

It has long been known that languages with otherwise similar definite/indefinite article use, such as English and Dutch on the one hand and Romance languages on the other, contrast with respect to the forms they use for plural generics. It is this contrast that we set out to account for. In this section, we review the relevant data and extend the empirical domain to include Hungarian and Greek, which, it turns out, behave like the Romance group. In the next section, we set out our assumptions, and in Section 3 we develop the analysis. Section 4 shows that our treatment makes correct predictions concerning otherwise puzzling novel facts involving pseudo-genericity and anaphoric genericity.

\subsection{Episodic contexts}

The languages we are interested in use definite and indefinite articles, and have singular and plural forms. We focus here on the choice between definite and indefinite forms in generic environments, and therefore languages that do not systematically mark this contrast are not relevant to our classification (see Chierchia 1998, Dayal 2004, de Swart and Zwarts 2006 for discussion of such languages).

While there are some differences between the languages under consideration concerning definiteness and number in non-generic environments, the similarities are 
striking. We observe first that definite forms are uniformly used with unique (or maximal) referents, such as (1) and familiar referents, whether singular (2) or plural (3). We exemplify with English (E), French (F) and Hungarian (H):

(1) a. The moon is round. The stars are shining. E

b. La lune est ronde. Les étoiles brillent. F The moon is round. The stars shine.

$\begin{array}{lll}\text { c. A hold kerek. } & \text { A csillagok csillognak. }\end{array}$ the moon round the star.Pl shine.Pl

(2) a. A man and a child came in. The man was tall. E

b. Un homme et un enfant entraient. L'homme était grand. F A man and a child came-in. The man was tall.

c. Bejött egy férfi és egy gyerek. A férfi magas volt. H in.com.Past a man and a child the man tall was

(3) a. Children and dogs were playing in the street. The children were noisy. E b. Des enfants et des chiens jouaient dans la rue. Les enfants faisaient du bruit. F Indef-pl children and indef-pl dogs played in the street. The children made indef-mass noise.

c. Gyerekek és kutyák játszottak az utcán. A gyerekek hangosak voltak. H child.Pl and dog.Pl play.Past.Pl the street.on the child.Pl noisy.Pl were.Pl 
In Hungarian and English, bare plural forms are used with existential indefinite interpretations as in $(3 a, c)$ while in French the indefinite plural article des $(3 b)$ is found. Bare plurals and des NPs share many syntactic and semantic properties, as shown by Bosveld-de Smet (1998); for the purposes of this paper, they will be treated uniformly as indefinite plural forms. The point we have established so far is that the languages under consideration pattern alike in episodic contexts with respect to the choice between definite and indefinite forms.

\subsection{Generic constructions}

The term 'generic construction' covers both sentences expressing direct kind reference and those involving generic generalizations. Carlson (1977) introduces kinds as special ontological entities next to individuals and 'stages' (spatio-temporal 'slices' of individuals). We find direct reference to kinds in examples such as (4) and (6). Predicates like to be extinct do not apply to regular individuals like John and Fido, but only to species. Generic generalizations, exemplified in (5) and (7), express a property that generally applies to individuals realizing the kind. We refer to sentences involving reference to kinds and generic generalizations as 'generic constructions.' We take these sentences to have a particular syntactic configuration that qualifies as a construction, in a loose reference to the use of this term in construction grammar (Goldberg 2006 and references therein). Both singular and plural forms are used in the languages under consideration in both types of generic constructions. With singular NPs, the languages in both groups use a definite article for kind reference, as in (4), and an indefinite one in generic generalizations, as in (5): 
(4) a. The dinosaur is extinct. E

b. Le dinosaure a disparu. F

The dinosaur has disappeared.

c. A dinoszaurusz kihalt. H

The dinosaur die.out.Past

(5) a. A dog is dangerous when it is hungry. E

b. Un chien est dangereux quand il a faim. $\mathrm{F}$

A dog is dangerous when it has hunger

c. Egy kutya veszélyes mikor éhes. H

A dog dangerous when hungry

Differences arise in the plural case, where English-type languages use indefinite (bare) plural forms in generic environments, while Hungarian, Greek and Romance languages use definite plurals. We add a few more languages to show the consistency in the pattern for direct kind reference (6) and generic generalizations (7):

(6) a. Dinosaurs are extinct. E

b. Dinosaurussen zijn uitgestorven. Dutch

Dinsosaurs are extinct.

$\begin{array}{ll}\text { c. Les dinosaures ont disparu. } & \mathrm{F}\end{array}$

The dinosaurs have disappeared. 
d. A dinoszauruszok kihaltak. H the dinosaur.Pl die.out.Past.Pl

e. Dinosaurii au dispărut. Romanian

Dinosaur-def has disappeared.

f. Gli elefanti di colore bianco sono estinti. Italian

The elephants of colour white are extinct.

g. Oi asproi elephantes echoun exaphanistei. Greek

The white elephants are extinct.

(7) a. Dogs are dangerous when they are hungry. E

b. Honden zijn gevaarlijk wanneer ze honger hebben. Dutch

Dogs are dangerous when they hunger have.

c. Les chiens sont dangereux quand ils ont faim. F

The dogs are dangerous when they have hunger.

d. A kutyák veszélyesek mikor éhesek. H

the dog.Pl dangerous.Pl when hungry.Pl

e. Cîinii sînt intelegenți. Romanian

Dog-def are intelligent.

f. Gli ucelli di zone paludose sono intelligeni. Italian

The birds from marshlands are intelligent.

g. Ta skillia einai eksipna. Greek

The dogs are intelligent. 
The pattern is strong enough to create grammaticality contrasts. In English, definite plural generics are not normally expressed with definite forms, and sentences like (8a) are only felicitous in special contexts (cf. section 4.2 below). Similarly, bare plurals are perceived as ungrammatical in standard generic environments in languages like Italian, Hungarian and Greek:

(8) a. ??The dinosaurs are extinct. $\mathrm{E}$

b. *Elefanti di colore bianco sono estinti. Italian Elephants of colour white are extinct.

c. *Ucelli di zone paludose sono intelligenti. Italian Birds from marshlands are intelligent.

d. *Kutyák veszélyesek mikor éhesek. $\mathrm{H}$ dog.Pl dangerous.Pl when hungry.P1

e. *Asproi elephantes echoun exaphanistei. Greek White elephants are extinct.

The contrast between definite and indefinite generics is sometimes related to the contrast between Romance and Germanic languages, but the fact that typologically unrelated languages like Hungarian and Greek pattern with Romance indicates that we are dealing with a widespread phenomenon. Our primary aim is to account for the contrast between the (a/b) and (c-g) sentences of (6) and (7), while maintaining the similarities in (4) and (5), as well as (1)-(3). Given that the cross-linguistic variation is restricted to plural generics, an explanation that maintains a uniform analysis of the 
definite/indefinite contrast and the singular/plural distinction, and that is grounded in a general view of genericity is preferable over a theory that posits distinctions between languages or language families in these domains. So we start by outlining our background assumptions concerning genericity, number, and (in)definiteness.

\section{Background assumptions}

\subsection{Number interpretation}

We follow the treatment of number interpretation in Farkas and de Swart (2003) and Farkas (2006), according to which singular nominals are semantically and morphologically unmarked for number, while plural nominals are morphologically marked by the feature $[\mathrm{Pl}] .{ }^{1}$ The atomic interpretation of singular NPs is the result of the fact that assignment functions give discourse referents atomic values by default. The effect of the feature $[\mathrm{Pl}]$ is to introduce a presupposed discourse referent that gets the predicate $\mathrm{Pl}($ ural) predicated of it, thereby allowing both atoms and groups as possible values for this referent. Thus, the presence of $[\mathrm{Pl}]$ opens up the whole lattice as the possible value domain for the relevant discourse referent. ${ }^{2}$

\section{2 (In)definiteness}

\footnotetext{
${ }^{1}$ A possible morpho-syntactic implementation of this idea is to have an equipollent morphosyntactic feature $[\mathrm{Pl}]$ whose absence has no direct semantic import.

${ }^{2}$ A lattice is a partially ordered set with two operations (meet and join) defined over members of the set (Partee, ter Meulen and Wall 1990: 281). Intuitively, the lattice formed by the denotation of $d o g$ is a structure whose elements are all the individual dogs in the model as well as all the possible sums of these individuals. Link (1983) showed that we can use the algebraic structure of a lattice to describe the semantics of plurals and mass nouns.
} 
As mentioned above, we take an NP to be definite when it is preceded by the definite article, and indefinite if preceded by an indefinite article or if it is a bare plural. There are two fundamental issues that arise in connection with definiteness distinctions: (i) what property or properties are encoded in definite and indefinite forms, and (ii) is the contrast symmetric, with definites and indefinites imposing opposing requirements or asymmetric, with definites marked as imposing a requirement, and indefinites as unmarked relative to it.

With respect to the first issue, the main competitors have been uniqueness/ maximality and familiarity. In dynamic approaches such as ours, both properties concern the discourse referent introduced by the NP in question. A discourse referent $u$ is maximal iff it ranges over all entities that satisfy its descriptive content. In the absence of a plural condition, maximality amounts to uniqueness. Whether a discourse referent is maximal or not is encoded in the discourse referent feature $[ \pm$ Max $]$. A discourse referent that is marked by $[+$ Max $]$ must have unique reference if atomic, and maximal reference otherwise. Familiarity concerns the question whether the discourse referent is present in the input context or not. The feature $[ \pm$ Fam $]$ on a discourse referent encodes its status with respect to this parameter. A discourse referent characterized as $[+F a m]$ must be familiar in the relevant situation or accommodatable therein. For convenience, an NP is said to be maximal or familiar when the discourse referent it introduces is maximal or familiar respectively. We assume that both maximality and familiarity play a role in definiteness. As an umbrella term for these two semantic properties, we adopt the dynamic notion of determined reference (from Farkas 2002). 
With respect to the second issue, we follow Hawkins (1991) and others in assuming an asymmetrist position: definite forms impose a semantic requirement with respect to which indefinite forms are neutral. We deal here only with the least marked of the definite markers, namely the definite article. The semantic contribution of the definite article in all the languages under consideration is to impose the requirement of determined reference on their discourse referent (marked as $! u$ in the DRS).

Indefinite NPs on the other hand do not impose maximality/familiarity restrictions on the discourse referent they introduce. As a result, discourse referents introduced by indefinite NPs may, in principle, be maximal or familiar. In the optimality theoretic approach we give below, the definite form will emerge as the preferred one in case the discourse referent is both maximal and familiar. Non-familiarity and nonmaximality is associated to indefinite forms as a conversational implicature triggered by the choice of an indefinite form over a definite one. In episodic contexts like the first sentences of (2) and (3), the status of the discourse referent with respect to the two features associated with definiteness is not recoverable from the semantics of the sentence itself. The choice of a definite article in such cases signals uniqueness and familiarity, while the use of an indefinite implicates the absence of these properties. Horn (2005), Farkas (2006), and de Swart (2006) propose similar treatments. For an influential 'symmetrist' account of the definite/indefinite contrast, see Heim (1982).

\subsection{An OT analysis}

The aim of the paper is to complement the interpretive perspective developed so far with a generative analysis of article choice. The key question here is what determines 
article choice for the speaker. De Swart and Zwarts (2006) work out an OT typology of nominal structure covering a wide range of languages. In this paper, we limit ourselves to the expression of plurality and definiteness in languages that have a singular/plural distinction and a definite/indefinite contrast in the determiner system. As far as the syntactic structure of nominals is concerned, we assume that full DPs have the layered structure $\left[{ }_{\mathrm{DP}} \mathrm{D}[\mathrm{NumP}[\mathrm{NP}]]\right.$, with articles residing in D. All nominals project at least at the lexical level of NP. Whether nominals have a NumP or a DP projection depends on the presence of number morphology on the noun and on the presence of articles. The relevant faithfulness constraints governing the singular/plural distinction and the use of the definite article (from de Swart \& Zwarts 2006) are the following:

- FPl: parse plurality by means of a NumP.

- FDef: determined reference needs to be parsed.

$\mathrm{FPl}$ requires the projection of a NumP with a $[\mathrm{Pl}]$ feature on the noun if the input involves a plural discourse referent. FDef requires the syntax to mark the fact that a discourse referent has determined reference in the semantic input. The standard way of satisfying FDef is by means of a definite article, but we see in section 3 that there are other possibilities as well.

In many languages, some or all of the faithfulness constraints governing number and article use are ranked below markedness constraints blocking functional structure in the nominal domain. In these languages, no morphological number is realized on 
nominals, and there is no definite/indefinite contrast (see de Swart and Zwarts 2006 for examples). In the languages we are concerned with here, the two faithfulness constraints are both ranked higher than the markedness constraints blocking functional structure. This results in the projection of NumP and DP, whenever required. The two language groups (English/Dutch and Romance/Hungarian) both have a singular/plural constrast as well as definite/indefinite articles, so they have the same constraint ranking as far as FPl and FDef is concerned. The ranking of these faithfulness constraints explains why these languages pattern alike in episodic contexts, as outlined in section 1.1 above. ${ }^{3}$ The constraint ranking in the languages we are concerned with also accounts for the cross-linguistic stability we find in singular generics. Showing this, however, is non-trivial, and lack of space prevents us from going into it here. We refer the reader to Farkas and de Swart (2006) for a more elaborate treatment of cross-linguistic stability.

Obviously, if the constraint ranking proposed so far is the same for both language groups considered here, it does not account for the cross-linguistic variation in plural generics outlined in section 1.2. Languages that have the same OT grammar, should behave in the same way as far as article choice is concerned. The analysis we propose in section 3 involves the interaction of two new constraints that are differentially ranked in the two classes of languages. In order to motivate their relevance for plural generics, we spell out our assumptions about genericity in subsection 2.4.

\footnotetext{
${ }^{3}$ As Horn (2005) points out, the constraint ranking proposed in de Swart \& Farkas (2005) does not account for the cross-linguistic stability between English/Dutch and Romance/Hungarian in episodic contexts. Placing our account of the plural generics within the more general view of the syntax and semantics of the definite/indefinite contrast and the typology in de Swart \& Zwarts (2006) allows us to avoid the problem Horn raises. See Farkas and de Swart (2006) for more extensive discussion.
} 


\subsection{Genericity}

Since Carlson's (1977) seminal work, bare plurals and the expression of genericity have been intimately related in a literature too vast to review here. The issue of genericity and definiteness has been central to early works such as Gerstner and Krifka (1989), and more recently, Dayal (2004). The particular problem we are concerned with here has been discussed by Vergnaud and Zubizaretta (1992), Krifka et al. (1995), de Swart (1996), Longobardi (1994, 2001), Zamparelli (2002), Robinson (2005), Behrens (2005). However, neither a (neo-)Carlsonian approach, nor an unselective binding theory of genericity seems to offer an immediate solution to the cross-linguistic variation in article choice (as argued by de Swart and Farkas 2005). In the interest of space we outline below only those aspects of genericity that are of immediate relevance to us.

We assume that existential interpretations of indefinite plurals, whether bare or not, exemplified in (3), involve ordinary plural indefinites, bound by an external existential quantifier. In DRT, they are treated as introducing a discourse referent $u$ with a condition of plurality on $u$, written $P l(u)$. With respect to singular nominals in generic constructionss, Farkas and de Swart (2006) follow Carlson's (1977) original insight in treating the definite singular in (4) as referring to a special atom $k$ in the model, one that is kind-level and unique. We follow Farkas and Sugioka (1983), Diesing (1992), Krifka et al. (1995) and others, in treating the indefinite singular in generic generalizations like (5) as an ordinary indefinite, introducing a discourse referent $u$ that is interpreted in the restrictor of a silent generic operator Gen. Gen is 
similar in status to an adverbial quantifier like always, usually, generally, but remains implicit. Such adverbs are taken to be unselective quantifiers in Kamp (1981) and Heim (1982), so they bind all the variables in their scope. However, de Swart (1991, 1996) takes quantificational adverbs to be quantifiers over events or situations. We follow her approach, and adopt an event-based interpretation of Gen. The sentences in (5) get the DRT representation in figure 1, where Gen binds dog-sized situations. The individual variable $u$ is indirectly bound by Gen, because it strictly co-varies with the situation (de Swart 1991, 1996). We signal such indirect binding by subscripting the Gen operator with the situation variable $s$ as well as the individual variable $u$.

Figure 1: DRT representation of indefinite singulars in generic generalizations

\section{A dog is dangerous when it is hungry.}

\begin{tabular}{|l|l|}
\hline \multicolumn{1}{c|}{$\mathrm{u}, \mathrm{s}$} \\
$\operatorname{dog}(\mathrm{u}, \mathrm{s})$ \\
$\operatorname{hungry}(\mathrm{u}, \mathrm{s})$
\end{tabular}$\quad \operatorname{Gen}_{\mathrm{s}, \mathrm{u}} \quad$ dangerous $(\mathrm{u}, \mathrm{s})$

We extend Ferreira's (2005) analysis of the habitual operator to generic sentences. Ferreira interprets the habitual operator as a plural definite ranging over events. We exploit this insight, and use our analysis of plurality and definiteness to propose an interpretation of Gen as a maximizing intensional operator over events that indirectly binds the generic nominal. The first argument of Gen (the restrictor) is the maximal 
set of typical situations in which the descriptive content is true, that is all situations in all worlds involving typical hungry dogs.

We take the plural in generic constructions like (6) to denote a kind. However, the kind referred to by the subject is not the atomic kind we find in (4), but a constructed kind. The sentences in (6) have the DRT representation in figure 2 , where $\sum$ is a plural sum operator. $\sum(\operatorname{dinosaur}(x, w))$ creates a kind-level entity by summing up all entities in all worlds that are dinosaurs in those worlds.

Figure 2: DRT representation of plural generics (kind reference)

Dinosaurs are extinct.

$\mathrm{K}$
$\mathrm{K}=\sum(\operatorname{dinosaur}(\mathrm{x}, \mathrm{w}))$
$\mathrm{Pl}(\mathrm{K})$
extinct $(\mathrm{K})$

In our view, there are two ways of obtaining kind-level entities: either by referring to the atomic kind-level individual directly or by getting to the kind via the plural sum $\sum$ operator, which constructs a kind by summing up all its realizations in the model. The $\sum$ operator is our analogue of the $\cap$ operator in Chierchia and Dayal's work, and is inspired by Ojeda's (1993) mereological approach. $\sum$ is a partial function, because all kinds are constructed as sums, but not all sums qualify as kinds. ${ }^{4}$ The entity that

\footnotetext{
${ }^{4}$ As an anonymous reviewer correctly points out, the summing up of all the entities satisfying the descriptive content of the noun in all worlds in the model does not always lead to a well-formed kind interpretation. In particular, sentences like (i) are hardly acceptable in English, and their Romance counterparts only have an episodic interpretation (e.g. French ii).

(i) ??Dogs I owned are extinct.
} 
results after application of $\sum$ is the top node of the intensional lattice associated with the descriptive content of the plural NP. We denote it by $K$ to distinguish it from ordinary atomic kinds $k$ (which can form their own hierarchical structures in taxonomic interpretations). Kind-level predicates like to be extinct are insensitive to the difference between atomic kinds $(k)$ and derived kinds $(K)$, as illustrated by the felicity of both (4) and (6).

We treat the generic generalizations in (7) as essentially analogous to (5) except for the presence of the plural condition. The representation is given in figure 3 .

Figure 3: DRT representation of plural generics (generic generalizations)

Dogs are dangerous when they are hungry.

\begin{tabular}{|l|l|}
\hline \multicolumn{1}{|c|}{$\mathrm{u}, \mathrm{s}$} & \\
$\operatorname{dog}(\mathrm{u}, \mathrm{s})$ & Gen $_{\mathrm{s}, \mathrm{u}} \quad$ dangerous $(\mathrm{u}, \mathrm{s})$ \\
$\mathrm{Pl}(\mathrm{u}, \mathrm{s})$ & \\
hungry $(\mathrm{u}, \mathrm{s})$
\end{tabular}

(ii) Les chiens que j'ai eu ont disparu.

[French]

In line with Chierchia's claim that $\cap$ is a partial function from properties to kinds, we assume that all kinds denote the sum of the plural (intensional) lattice, but not all sums correspond to a kind. The $\sum$ operator will be undefined for NPs like dogs I owned. We leave open here the issue of why this is so. 
We are glossing over the issue of connecting individuals to their stages, as well as over the presence of a distributive operator that guarantees that the predication over the plural entity percolates down to its atomic members. Neither issue is relevant to our present concerns.

Figures 2 and 3 abstract away from the contrast between definite and indefinite plural generics, and focus on their common semantic core and identical truth conditions. In Section 3.4 below, we adopt Figure 3 as the final representation for the English sentence and a preliminary representation for its French counterpart. The final version for plural generic generalizations involving definites will reflect the contribution of the definite article. However, the truth conditions of the two DRSs are the same, so the contrast between definite and indefinite NPs is in fact neutralized in generic contexts. Explaining how the contrast is neutralized in the case of plural generics is the issue pursued in section 3 .

\section{Article choice in plural generics}

In this section we give a generative analysis of article choice in plural generics that mirrors the interpretive perspective deveoped in section 2. We spell out an expressive optimization process which takes well-formed semantic representations in DRT format with a specification of the feature values concerning familiarity and maximality as its input. The output consists of possible candidate forms in the language at hand, which vary in their use of a definite or an indefinite article. The 
starting point is the claim that the generic construction satisfies FDef in these cases, which explains why the contrast between definite and indefinite NPs is neutralized in plural generic contexts (section 3.1). If FDef does not govern article choice in generic contexts, we need to define further constraints that regulate article selection. Given that the way the generic construction satisfies FDef is by means of maximality, not by means of familiarity, we split up the notion of determined reference and define two new subconstraints, viz. *Def/[-Fam] and MaxMax (section 3.2). The two ways of ranking these two constraints are responsible for the choice between definite and nondefinite plural generics (section 3.3). In section 3.4, we show how the input meaning is recovered in both classes of languages.

\subsection{The generic construction satisfies FDef with plural generics}

Section 1.2 distinguishes two types of generic constructions. Generic generalizations involve a Gen operator, and direct reference to kinds in sentences with plurals involves the plural sum operator $\Sigma$ (section 2.4). The generic construction induces determined reference of the discourse referent in both cases. In generic generalizations, Gen indirectly binds the discourse referent introduced by the generic plural NP, because the situations under consideration are individual-sized. Given the semantics of Gen as a plural definite operator over events, it confers maximality upon the discourse referent it indirectly binds because this discourse referent ranges over all possible entities that meet the descriptive content. This discourse referent then has determined reference because it is bound by Gen. In direct reference to kinds, the 
plural sum operator confers maximality onto the discourse referent introduced by the generic plural, because it collects all the realizations of the kind in the model.

Recall from section 2.3 that FDef requires parsing of determined reference in all languages under consideration. We take FDef to be satisfied by the generic construction, which induces determined reference both in reference to kinds and generic generalizations. Given that FDef is satisfied independently by the generic construction, this constraint is not relevant to article choice in the nominal. We turn in section 3.2 to the issue of how article choice is governed in generic plurals.

\subsection{Two constraints governing determined reference}

If FDef is satisfied by the generic construction, it does decide between definite and indeefinite plural generics. New constraints are needed to govern article choice of plural generics. In this section we introduce the relevant constraints. We then show how their different ranking is responsible for cross-linguistic variation in article choice (section 3.3). We close by showing how the same meaning is recovered despite variation in form (section 3.4). In section 4 we turn to data that confirm the analysis.

The discourse referent introduced by a plural generic nominal has determined reference because maximality is conferred upon it by the plural sum operator $\Sigma$, or as a result of indirect binding by the Gen operator. In Heim (1982) and Kamp \& Reyle (1993), discourse referents (in)directly bound by an operator in the Restrictor always carry a new index, so they are taken to be non-familiar. The plural kind $\mathrm{K}$ defined as 
the sum of the realizations of the kind in the model is also a non-familiar discourse referent, because of the intensional nature of the $\Sigma$ operator. Plural generics then introduce maximal non-familiar discourse referents in both types of generic constructions. In this context, the two parameters of determined reference (i.e. maximality and familiarity) are independent. In the perspective of expressive optimization, we can capture the two aspects of determined reference in the two constraints in (11) and (12):

(11) MaxMax: Maximize maximality features of the discourse referent by reflecting them in the nominal projection.

(12) *Def/[-Fam]: Avoid non-familiar definites.

These constraints govern the choice of a definite or an indefinite nominal form based on the semantic properties of the discourse referent the nominal introduces. MaxMax is a faithfulness constraint that requires a maximal discourse referent to be introduced by an NP with a definite article, even if determined reference is already reflected in the Gen operator. ${ }^{5}$ It is more specific than FDef: satisfaction of MaxMax entails satisfaction of FDef, but not the other way around. *Def/[-Fam] penalizes the use of a

\footnotetext{
${ }^{5}$ MaxMax is inspired by the constraint MaxNeg in de Swart (2006), which requires variables in the scope of negation to be marked as negative. That is, MaxNeg favors the use of n-words. Just like MaxNeg, MaxMax enforces agreement: a semantic feature of the input is necessarily formally reproduced on the nominal, even if it is already expressed elsewhere in the sentence.
} 
definite article with non-familiar discourse referents. ${ }^{6}$ It is also more specific than FDef, because it only comes into play in languages that have a definite/indefinite contrast. Accordingly, the ranking of the two constraints is only relevant in languages in which they are ranked below FDef, and above markedness constraints blocking functional projections in the nominal domain.

The constraints in (11) and (12) are universal, and therefore valid in all languages under consideration. The contrast of interest here is due, we argue, to different orderings of the two constraints below FDef. The two rankings are given below:
(13) FDef >>*Def/[-Fam] >> MaxMax
[English, Dutch]
FDef $>>$ MaxMax $>>*$ Def/[-Fam]
[Romance, Greek, Hungarian]

We predict cross-linguistic stability in the case of alignment of familiarity and maximality. We predict cross-linguistic variation in cases of non-familiar maximal discourse referents in contexts in which FDef is independently satisfied. In that case, English will use indefinite forms, while Hungarian/Romance/Greek will use definite ones. We see the conflict between the two constraints in plural generics because in these contexts FDef is independently satisfied by the generic construction.

\subsection{Working out the OT typology for generic plurals}

\footnotetext{
${ }^{6} \mathrm{Cf}$. Beaver (2004) for a different formulation of the same idea. We prefer the formulation adopted here, because it reflects the claim that it is the lack of familiarity in plural generics that is responsible for the blocking of the definite article in English generics.
} 
Our main point is that the details of number interpretation and genericity in plural generics lead to a conflict between the constraints *Def/[-Fam] and MaxMax. There are two cases to consider, represented in figures 2 and 3 above. In cases of plural kind level predications (Dinosaurs are extinct in figure 2) the subject refers to the top of the dinosaur lattice via the $\Sigma$ operator. We thus have a maximal discourse referent that is not, however, familiar. In the case of plural generic generalizations (Dogs are dangerous when they are hungry in figure 3) we have a plural discourse referent indirectly bound by the generic operator. The discourse referent here is maximal because it is indirectly bound by Gen. This discourse referent is not, however, familiar or accommodatable, exactly because of its being indirectly bound by Gen. Its values are selected from dogs in the situations bound by Gen and therefore those values cannot be assumed to be contextually given.

In plural generic cases, there is a conflict between the constraints in (11) and (12). The conflict can be resolved by relative ranking. 'High Familiarity' languages, such as English, rank *Def/[-Fam] above MaxMax, and use an indefinite form in these contexts, while 'high Maximality' languages, such as Romance and Hungarian give priority to MaxMax, and use a definite one. We illustrate with two tableaux for article choice in plural generic generalizations:

Tableau 1: indefinite plural generic generalizations (illustrated with English) 


\begin{tabular}{|l|l|c|c|}
\hline Meaning & Form & *Def/[-Fam] & MaxMax \\
$\operatorname{Gen}_{\mathrm{x}}(\operatorname{Dog}(\mathrm{x}), \mathrm{Pl}(\mathrm{x}))$ Intellig(x)) & & & \\
\hline$[+\mathrm{Max}][-\mathrm{Fam}]$ & Dogs are intelligent & & $*$ \\
\hline & The dogs are intelligent & $*$ & \\
\hline
\end{tabular}

Tableau 2: definite plural generic generalizations (illustrated with French)

\begin{tabular}{|l|l|c|c|}
\hline Meaning & Form & MaxMax & *Def/[-Fam] \\
Gen $\left._{\mathrm{x}}(\operatorname{Dog}(\mathrm{x}), \mathrm{Pl}(\mathrm{x})) \operatorname{Intellig}(\mathrm{x})\right)$ & & & \\
\hline$[+\mathrm{Max}][-\mathrm{Fam}]$ & & & \\
\hline & Des chiens sont intelligents & $*$ & \\
\hline & Les chiens sont intelligents & & $*$ \\
\hline
\end{tabular}

Both tableaux map a given input meaning (in DRT format, with specification of feature values concerning maximality and familiarity) to a number of candidate output forms that vary in article use. The input meaning is the same in both tableaux. It involves a discourse referent that has the features [+Max] and [-Fam], and that constitutes the topic of a generic generalization. The candidate output forms are definite or indefinite plurals. The choice of form is dictated by the ranking of the two constraints in the two languages. The same meaning can thus be expressed in two ways, and languages differ in the optimal form they associate with the mixed input of 
familiarity and maximality that is characteristic of plural generics in generic generalizations.

The case of plural generic subjects of kind level predicates is similar. Here it is the presence of $\sum$ that renders the relevant discourse referent maximal and nonfamiliar:

Tableau 3: indefinite reference to kind (illustrated with Dutch)

\begin{tabular}{|l|l|c|c|}
\hline Meaning & Form & *Def/[-Fam] & MaxMax \\
\hline$[+\mathrm{Max}][-\mathrm{Fam}]$ & & & \\
\hline & Dinosaurs are extinct & & \\
\hline & De dinosaurussen zijn uitgestorven & $*$ & \\
& The dinosaurs are extinct & & \\
& & & \\
\hline
\end{tabular}

Tableau 4: definite kind reference (illustrated with Hungarian) 


\begin{tabular}{|c|c|c|c|}
\hline $\begin{array}{l}\text { Meaning } \\
\text { Dinosaur }\left(\mathrm{x}_{\mathrm{k}}\right) \& \operatorname{Extinct}\left(\mathrm{x}_{\mathrm{k}}\right) \\
{[+\mathrm{Max}][-\mathrm{Fam}]}\end{array}$ & Form & MaxMax & $*$ Def/[-Fam] \\
\hline & $\begin{array}{l}\text { Dinoszauruszok eltüntek } \\
\text { dinosaurs are extinct }\end{array}$ & $*$ & \\
\hline 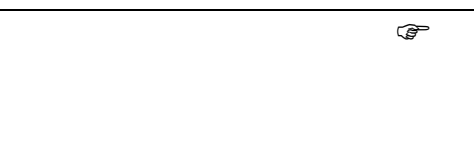 & $\begin{array}{l}\text { A dinoszauruszok eltüntek } \\
\text { The dinosaurs are extinct }\end{array}$ & & $*$ \\
\hline
\end{tabular}

Again, we see that the input is identical, but that the same meaning leads to two different optimal forms in two different languages, depending on the ranking of the constraints MaxMax and *Def/[-Fam]. In a regular optimality theoretic fashion, the 'winner takes all', so the sub-optimal forms in the tableaux are either ungrammatical, or realize a different input (cf. section 4 below). The examples (6)-(8) in section 1 illustrate that the optimization procedure in tableaux 3 and 4 gives the correct result.

It is clear from the tableaux that the features $[ \pm$ Max $]$ and $[ \pm$ Fam $]$ drive the article choice in generic environments. The value of these features for the relevant discourse referent is fixed in the context of the generic construction (Gen or $\sum$ ). Thus, it is the particular configuration of plurality and genericity that creates the mixed input that is responsible for the cross-linguistic variation we find. The solution we propose for the puzzle defined in section 1.2 above is that the cross-linguistic variation in article use in plural generics is the result of a competition between two constraints involved in the expression of determined reference. 


\subsection{Recovering the meaning}

The OT analysis developed in section 3.3 is driven by the idea that generic plurals give rise to a conflict between the two constraints that are involved in article selection in contexts in which FDef is independently satisfied. Article choice in these forms then depends on the relative ranking of two more specific constraints, MaxMax and *Def/[-Fam]. MaxMax militates for a definite form in generic plurals because the discourse referent is maximal. *Def/[-Fam], on the other hand, militates for an indefinite form in generic plurals because the discourse referent is novel. 'High Maximality' languages (Hungarian, Greek and Romance) resolve this conflict by adopting the ranking MaxMax $>>*$ Def/[-Fam], and use definite plurals in generic contexts. 'High Familiarity' languages (English, Dutch) use indefinite (bare) plurals in the same contexts because they adopt the reverse ranking.

The main question that arises at this point is how the different forms allow us to recover the input meaning. In other words, how can definite and indefinite generics convey the same semantics, given that the semantics of the determiners is different? The answer already anticipated in section 2.4 above is that the semantic contrast between definite and indefinite plurals is neutralized in generic contexts. We don't need OT semantics to achieve this result, for there is no competition between different possible meanings for one and the same sentence. In this section, we show that the assumptions we made in section 2 about the semantic contribution of the definite article, of the plural morphology on the noun and of the generic construction 
provide identical truth conditions for generic sentences involving definite or indefinite (bare) plurals.

Under the assumption that the definite/indefinite contrast is uniform across all contexts, the DRT representations in figures 2 and 3 are correct for English and Dutch generic plurals. For the Romance, Greek and Hungarian sentences in (6c-g) and $(7 \mathrm{c}-\mathrm{g})$, we need to build a DRS that includes the contribution made by the definite article. Recall from section 2.3, that definite NPs impose determined reference on their discourse referent. Determined reference is noted by $! u$ in the DRS (Farkas 2002). The resulting DRS representation is spelled out in figures 4 and 5:

Figure 4: DRT representation of definite plural generics (kind reference)

\section{A dinoszauruszok kihaltak.}

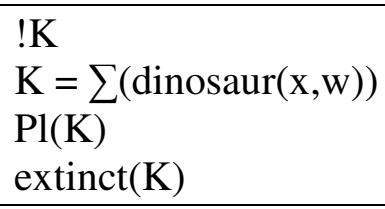

Figure 5: DRT representation of definite plural generics (generic generalizations) 


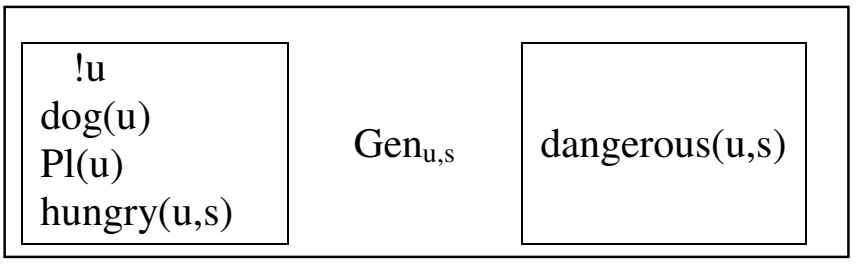

The DRSs in figures 2 and 4, and figures 3 and 5 are identical except for the marking of determined reference on the discourse referent $! K$ in figure 4 , and $! u$ in figure 5 , induced by the definite article. In order for $K$ and $u$ to have determined reference, the value assigned to these discourse referents in the model must be fixed, i.e., they must leave no choice in value assignment. In the case of figures 4 and 5, the generic construction confers maximality upon the discourse referent, because of the semantics of $\Sigma$ in Figure 4 and presence of Gen in Figure 5. But if it is the generic construction that guarantees maximality of the discourse referent, $K$ and $x$ are maximal in figures 2 and 3 as well, even though there is no encoding of this fact within the DRS. The contribution of the definite article in figures 4 and 5 is semantically redundant and therefore the DRSs in figures 2 and 4 as well as those in figures 3 and 5 have the same truth-conditions. If the DRSs have the same truth conditions, the sentences they represent are equivalent. MaxMax is then truly an agreement constraint, which operates in the syntax, but has no semantic impact.

The argumentation relies on the asymmetric analysis of the definite/indefinite contrast advanced in section 2.2. Definite NPs induce determined reference, indefinite NPs don't. Indefinites are underspecified with respect to determined reference, so they neither impose determined reference on the discourse referent they introduce, nor block it. If some other operator (in casu the generic construction) confers a 
maximal interpretation upon the discourse referent the plural introduces, the truth conditions of a sentence involving an indefinite (bare) generic plural are identical to those of the corresponding sentence with a definite generic plural. The general semantic contrast between definites and indefinites is thus effectively neutralized in the context of plural generics, and the English/Dutch sentences in (6a, b), (7a,b) are genuinely equivalent in meaning to their Romance/Greek/Hungarian counterparts in $(6 c-g)$ and $(7 c-g)$.

If sentences involving definite and indefinite plural generics are truly equivalent, we may wonder why natural languages do not freely use both. The fact that languages like English and Dutch rule out the use of the definite article in 'standard' generic statements, whereas Romance, Greek and Hungarian block indefinite/bare plurals in the same environments suggests that languages avoid full synonymy. This view can be taken to drive the expressive optimization procedure spelled out in section 3 .

The analysis set up for the contrast between the two groups of languages is based on the feature configuration [+Max], [-Fam $]$ in generic sentences expressing direct reference to kinds, and generic generalizations. In these environments 'high familiarity' languages use an indefinite form and 'high maximality' languages a definite one. Independent evidence in favor of our account could come from generic contexts in which the feature values are modified. The restriction to generic contexts is essential, for in these constructions, FDef is independently satisfied, so we can test our predictions with respect to the constraint MaxMax and *Def/[-Fam]. Suppose we have generic sentences in which the discourse referent is either [-Max] (and [-Fam]) or $[+F a m]($ and $[+M a x])$. In such cases, we predict the cross-linguistic differences to 
disappear because one of the relevant constraints would be vacuously satisfied. In section 4 , we consider two such cases, which we refer to as pseudo-genericity and anaphoric genericity and show that our predictions are confirmed.

\section{Non-standard genericity}

So far we have considered 'standard' instances of genericity in which plural generics are maximal, but non-familiar. This feature configuration triggers a conflict between MaxMax and *Def/[-Fam] that drives the cross-linguistic variation pattern. Here we explore the predictions of our account with respect to two special cases of nonstandard genericity involving plurals: (i) 'pseudo-genericity' and (ii) anaphoric genericity. Pseudo-generics are special because they lack maximality; anaphoric generics are special in that they involve familiar discourse referents. Our account predicts that the cross-linguistic contrast investigated here will be neutralized in favor of indefinite forms in the first case and definite forms in the latter.

\subsection{Pseudo-genericity}

In 'true' generic generalizations such as (5) and (7), the generic operator binds the variable introduced by the plural subject indirectly, by binding minimal situations in which there is an entity or group of entities realizing the descriptive content. The variable is maximal because present, past, future and possible typical dogs are all possible values for $u$ in figures 3 and 5 . It is, however, possible for the situation 
variable to be bigger, and include more than just the relevant individual. In such cases, there is no indirect binding, and the NP gets an existential interpretation. As a result, the set of situations quantified over is maximal but the individual discourse referent is not because Gen does not indirectly bind it. We refer to generic sentences that contain a nominal with the feature combination [-Fam $],[-$ Max $]$ as 'pseudogenerics.' If we evaluate the input meaning of a pseudo-generic sentence in the OT system developed in section 3, we observe that the constraint MaxMax is vacuously satisfied, in the absence of a feature [+Max]. The only relevant constraint is *Def/[Fam], resulting in the choice of an indefinite form. We therefore predict that the contrast between 'high Maximality' and 'high Familiarity' languages will be neutralized in these contexts in favor of the indefinite forms. Indeed, Longobardi (2001), Carlier (1989), Dobrovie-Sorin and Laca (2003), Dobrovie-Sorin (2004), Heyd (2003) observe that we find bare plurals (in Italian) and des NPs (in French) in contexts with event-based modifiers or modal auxiliaries. Some examples are given in (14) and (15):

(14) a. Ucelli di zone paludose sono ghiotti di insetti. Italian Birds of marshlands are eager for insects.

b. Elefanti di colore bianco possono creare grande curiosità White-coloured elephants can raise great curiosity.

(15) a. Des guêpes énervées sont un danger terrible. French Indef-Pl wasps irritated are a danger terrible 
b. Des grévistes peuvent ruiner une enterprise.

Indef-Pl strikers can ruin a company.

c. Des jeunes filles doivent se montrer discrètes.

Indef-Pl young girls have refl show discrete

d. Des enfants malades sont grincheux.

Indef-Pl children sick are grouchy

The semantics of pseudo-genericity involving an event-based modifier is spelled out in the DRS in figure 6.

Figure 6: Pseudo-genericity involving an event-based modifier

Des enfants malades sont grincheux.

\begin{tabular}{|l|}
\multicolumn{1}{c|}{$\mathrm{u}, \mathrm{s}$} \\
child(u) \\
$\mathrm{Pl}(\mathrm{u})$ \\
$\operatorname{sick}(\mathrm{u}, \mathrm{s})$
\end{tabular}

$\operatorname{Gen}_{\mathrm{s}} \quad \operatorname{grouchy}(\mathrm{u}, \mathrm{s})$

As usual, Gen is an intensional operator ranging over typical situations satisfying the restrictor. In figure 6, these are situations of sickness implicating children, which do not necessarily co-extend (luckily!) with the set of children. No indirect binding is involved, so the subscript on Gen is just $s$, and the discourse referent $u$ gets an existential interpretation within the restrictor. The sentence tells us that typically, 
situations of sickness implicating children lead the children in these situations to be grouchy. Under this interpretation, the discourse referent $u$ is non-maximal and nonfamiliar. In terms of our OT analysis, the vacuous satisfaction of MaxMax blocks the definite form, and requires the use of an indefinite form even in 'high Maximality' languages like Romance, which is indeed what we find. As observed by Heyd (2003), the type of adjective and predication used in such sentences is crucial in allowing an event-based pseudo-generic construal, and avoid indirect binding.

The semantics of pseudo-genericity involving a modal auxiliary is spelled out in the DRS in figure 7:

Figure 7: Pseudo-genericity involving a modal auxiliary

Des grévistes peuvent ruiner une enterprise

w, u, y
striker(u,w)
Pl(u)
company $(y, w)$
employee $(u, y, w)$

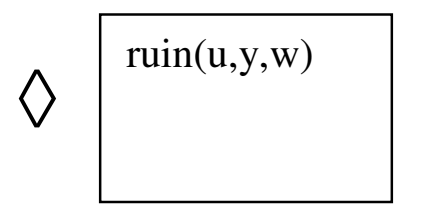

Thanks to the modal auxiliary, the generic generalization bears on worlds $w$ in which strikers $u$ are employed by a company $y$. The existential reading of strikers triggered by this configuration makes $u$ non-maximal. Non-maximality of the discourse referent implies that the constraint MaxMax is vacuously satisfied, and the constraint 
*Def/[-Fam] is decisive. The OT analysis thus predicts the use of an indefinite, rather than a definite form of the subject in all languages under consideration.

In the literature, the phenomenon of pseudo-genericity has been discussed for Italian and French. If this is really a phenomenon that correlates with the OT typology set up so far, we expect languages like Greek and Hungarian to use indefinite forms in pseudo-generic sentences as well. This prediction is borne out by the data. The Hungarian examples in (16) and the Greek examples in (17) mirror the Italian and French sentences in (14) and (15):

(16) a. Kiabáló gyerekek fárasztóak. Hungarian

Screaming child.Pl tiring.Pl

'Screaming children are tiring.'

b. Sztrájkolók tönkretehetnek egy vállalatot.

Striker.Pl ruin.Poss.Pl a company. 'Strikers can ruin a company.'

(17) a. Asproi elefantes mporoun na prokalsoun periergia. Greek White elephants can raise curiosity. b. Arosta pedeniá pu kléne sinéhia ine polí enohlitiká.

Sick children that cry all the time are very annoying.

Both Hungarian and Greek use bare plurals rather than definite plurals in contexts that involve event-based modifiers or modal auxiliaries to express pseudo-genericity. 
It is easy to find minimal pairs of definite and indefinite generic sentences. The French example in (15d) for instance has a counterpart in which the subject is definite (18a), and so does the Hungarian example (16a) in (18b):

(18) a. Les enfants malades sont grincheux.

'The sick children are grouchy

b. A kiabáló gyerekek fárasztóak. Hungarian

'The screaming children are tiring.'

Under its generic reading, sentence (18a) exemplifies a regular generic generalization over sick children as a subkind of children, and therefore the plural NPs introduce a maximal non-familiar discourse referent. We predict, correctly, the use of a definite form in 'high Maximality' languages here. The DRS in figure 8 gives the semantics for (18a), and is to be contrasted with the DRS in figure 6 .

Figure 8 Genericity involving subkinds

Les enfants malades sont grincheux

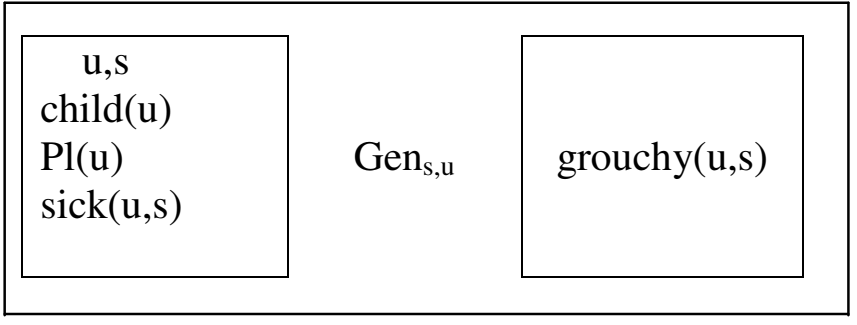


Whereas the DRS in figure 8 expresses a standard generic generalization over the properties of sick children as a subkind of children, the DRS in figure 6 talks about sickness situations involving children. The Gen operator in figure 8 bears the subscripts $s$ and $u$ signaling indirect binding (section 2.4), whereas the Gen operator in figure 6 only binds the situation variable $s$, and $u$ is existentially closed within the restrictor. It is quite possible that the two DRSs involve the same real world situations, but their linguistic forms, and semantic representation are distinct in 'high Maximality' languages. Of course, we can build the same semantic representations for languages like English and Dutch, but the realization of both standard generic generalizations and pseudo-genericity involves a bare plural, so it is much harder to distinguish the nuances of meaning in these languages.

\subsection{Anaphoric genericity}

In section 4.1 above, we saw that the contrast between the two groups of languages we consider is neutralized in favor of indefinite forms in pseudo-generics. We examine here the opposite situation, namely cases where true generic NPs are discourse old. In such cases the relevant variable will be both maximal and familiar and we predict definite forms across the board.

Contexts where kind reference is anaphoric are found in encyclopedia articles dealing with natural kinds. In such articles, once the kind itself is introduced, it becomes familiar and therefore we predict that English-type languages will use a 
definite plural to refer to it. This is indeed what we find, as exemplified in (19), taken from an article on dinosaurs. The heading is the first mention of the subspecies and is, as we expect, a bare plural. The first sentence in the paragraph starts with a definite plural because the kind is now discourse old.

(19) Saurischian Bipeds - The saurischians were the first of the two great groups to assume prominence. [...] From certain of these forms, the saurischians were certainly derived. (Encyclopaedia Britannica, 1972, p. 456)

In (19), we have a kind-level predicate whose subject refers, anaphorically, to a kindlevel discourse entity introduced earlier by means of a bare plural generic.

We expect definite plural forms in case of individual level predicates as well. Even though the variable is indirectly bound by the generic operator, because of previous mention of dinosaurs, it counts as familiar. A relevant example is given in (20).

(20) The coelurasaurs [...] were slender-limbed, lightly-build [...] and obviously fast-running forms that appear to have prayed upon their smaller reptilian contemporaries. (Encyclopaedia Britannica, 1972, p. 475)

Because the ban against using non-familiar definites is now irrelevant, English type languages use definite NPs with generic reference in anaphoric contexts. Similar examples are found in Dutch: 
(21) Dus de dieren die wij dinosaurussen noemen zijn echt uitgestorven. (...) Het is niet precies bekend hoe de dinosaurussen zijn uitgestorven. So the animals we call dinosaurs are really extinct. (...) It is not exactly known how the dinosaurs died out. [http://www.dinosaurus.net/AlgemeneInfo/Uitsterven/uitsterven.htm]

The observation that anaphoricity makes it possible to use definite plural generics in 'high Familiarity' languages indicates that a more dynamic, discourse oriented analysis of genericity is required. The ease with which anaphoric interpretations are construed might also be the key to some of the variation we find within high Familiarity languages. It seems that in German, Norwegian, and certain dialects of Dutch, definite plural generics are quite frequent, but the discourse conditions under which they occur are currently understudied. In line with Behrens (2005) and Oosterhof (2006), we suggest that more corpus-based research is required to get a better grip on the role that anaphoricity plays in the expression of genericity in these languages.

The facts reviewed in this section provide support for the claim that (in)definiteness in plural generics in the languages under consideration is sensitive to the two parameters of familiarity and maximality that make up the notion of determined reference.

\section{Conclusion}


The analysis presented in this paper accounts for the divergence between English/Dutch type languages and Romance/Hungarian when it comes to the use of definite and indefinite forms in generic plurals by positing two universal constraints, and deriving the cross-linguistic variation from a difference in the ranking of these constraints. It predicts that instances of cross-linguistic variation will be found in cases where we have maximal non-familiar (and non-accomodatable) reference. Teasing apart familiarity and maximality in article choice is crucial in accounting for the neutralization of the cross-linguistic contrast we studied here in cases of pseudogenericity and anaphoric genericity. A general lesson to be drawn from our discussion is that generic environments are useful when studying definiteness contrasts because their semantics makes definiteness marking redundant. Above we focused on accounting for cross-linguistic contrasts in the choice of definite versus indefinite forms. An account of cross-linguistic stability in article choice must be left for a different occasion (see Farkas and de Swart 2006).

\section{Acknowledgments:}

We are grateful to audiences at the LSA summer school at Harvard University, the ESSLLI summer school in Edinburgh, and the workshop 'QP structure, nominalizations and the role of DP' in Saarbrücken, as well as colleagues in Utrecht, Paris and Santa Cruz and to two anonymous referees for helpful discussion and comments on earlier versions of this paper. The second author would like to thank the Netherlands Organization for Scientific Research (NWO) for financial support (grant 051-02-070 for the Cognition project Conflicts in Interpretation, and grant 365-70- 
015 for her sabattical), and the Netherlands Institute for Advanced Study in the Humanities and Social Sciences (NIAS) in Wassenaar for their hospitality during the academic year 2005-2006.

\section{References}

Abbott, B. (1999). Support for a unique theory of definite descriptions. Proceedings of SALT IX, 1-15.

Abbott, B. (2003). A reply to Szabó's “Descriptions and Uniqueness.”Philosophical Studies 113: 223-31.

Beaver, D. (2004). The optimization of discourse anaphora Linguistics and Philosophy 27, 3-56.

Behrens, L. (2005). Genericity from a cross-linguistic perspective, Linguistics 43, 275-344.

Bosveld-de Smet, L. (1998). On mass and plural quantification: the case of French 'des'/'du’ NPs. PhD Dissertation, University of Groningen.

Carlier, A. (1989). Généricité du syntagme nominal sujet et modalités, Travaux de Linguistique 19, 33-56.

Carlson, G. (1977). Reference to kinds in English, PhD University of Massachusetts at Amherst; published 1980 New York: Garland.

Carlson, G. and J. Pelletier (1995) (eds.). The generic book, University of Chicago Press. 
Chierchia, G. (1998). Reference to kinds across languages, Natural Language Semantics 6, 339-405.

Dayal, V. (2004). Number marking and (in)definiteness in kind terms, Linguistics and Philosophy 27, 393-450.

Diesing, M. (1992). Indefinites, Boston: MIT Press.

Dobrovie-Sorin, C. et B. Laca (2003). Les noms sans déterminant dans les langues romanes, in: D. Godard (éd.) Les langues romanes-Problèmes de la phrase simple. Eds. du CNRS, 235-281.

Dobrovie-Sorin, C. (2004). Generic plural indefinites and (in)direct binding, in: F. Corblin et H. de Swart (éds.) Handbook of French Semantics, Stanford : CSLI Publications.

Farkas, D. (2002). Specificity distinctions, Journal of Semantics 19: 1-31.

Farkas, D. (2006) The unmarked determiner, to appear in L. Tasmowski and S. Vogeleer (eds.) Non-Definiteness and Plurality, Amsterdam : Benjamins.

Farkas, D. and Sugioka (1983). Restrictive if/when clauses, Linguistics and Philosopy 6 :225-258.

Farkas, D. and H. de Swart (2003). The semantics of incorporation : from argument structure to discourse transparency. Stanford: CSLI Publications.

Farkas, D. and H. de Swart (2006). Stability and variation in article choice: generic and episodic contexts, in: A. Giannakidou and M. Rathert (eds.). Quantification, nominalization and definiteness, Oxford: Oxford Unviersity Press (to appear). 
Ferreira, M. (2005). Bare habituals and plural definite descriptions, Proceedings of Sinn und Bedeutung 9, Nijmegen, 102-115. See: http://www.ru.nl/ncs/sub9/ Gerstner, C. and M. Krifka (1989). Genericity in : J. Jacobs et al. (eds.) Syntax: an international handbook of contemporary research, Berlin: De Gruyter.

Goldberg, A. (2006). Constructions at Work: the nature of generalization in language. Oxford University Press.

Hawkins, J. (1991). On (in)definite articles: implicatures and (un)grammaticality predictions, Journal of Linguistics 27, 405-442.

Heim, I. (1982) The semantics of definite and indefinite NPs, PhD diss. University of Massachusetts at Amherst.

Heyd, S. (2003). L'interprétation des syntagmes nominaux en "des" et "de" en position sujet et objet - Généricité, habitualité et incorporation sémantique, PhD thesis, Université Marc Bloch (Strasbourg)

Horn, L. (2005). <the, a>: (In)definiteness, implicature and scalar pragmatics, ms. Yale University.

Kamp, H. (1981). A theory of truth and semantic representation, in: J. Groenendijk et al. (eds.). Formal methods in the study of language, Amsterdam: Mathematical Centre. Reprinted in J. Groenendijk et al. (eds.) (1983). Truth, representation and information, Dordrecht: Forics, 277-322.

Kamp, H. et U. Reyle (1993). From discourse to logic. Dordrecht : Kluwer Academic Press.

Krifka, M. et al. (1995) Genericity: an introduction, in: G. Carlson and F. Pelletier (eds.) The Generic Book, Chicago: University of Chicago Press, 1-124. 
Link, G. (1984). The logical analysis of plurals and mass terms, a lattice-theoretic approach, in: R. Bäuerle et al. (eds.). Meaning, use and interpretation of language, Berlin: De Gruyter, 302-323.

Longobardi, G. (1994). Reference and proper names, Linguistic Inquiry 25 : 609-665. Longobardi, G. (2001). How comparative is semantics? A unified parametric theory of bare nouns and proper names, Natural Language Semantics 9 : 335-369.

Ojeda, A. (1993). Linguistic individuals, Stanford : CSLI Publications.

Oosterhof, A. (2006). Some aspects of the syntax and semantics of generics in Dutch, PhD diss. Gent (in progress).

Partee, B., A. ter Meulen and R. Wall (1990). Mathematical methods in linguistics, Dordrecht: Kluwer.

Robinson, H. (2005). Unexpected (in)definiteness: plural generic expressions in Romance, PhD Dissertation, Rutgers University.

de Swart, H. (1991). Adverbs of quantification: a generalized quantifier approach. PhD. Diss. Groningen; published 1992 by Garland, New York.

de Swart, H. (1996). (In)definites and genericity, in : M. Kanazawa et al. (eds.). Quantifiers, deduction and context, CSLI Publications, p. 171-194.

de Swart, H. (2006). Aspectual implications of the semantics of indefinite plurals, to appear in L. Tasmowski and S. Vogeleer (eds.) Non-Definiteness and Plurality, Amsterdam: Benjamins.

de Swart, H. and D. Farkas (2005). Généricité et indéfinitude. Une analyse dans la théorie de l'optimalité, in: C. Dobrovie-Sorin (ed.). Noms nus et généricité, Paris: Presses Universitaires de Vincennes, 97-126. 
De Swart, H. and J. Zwarts (2006). Less form, more meaning: why bare nominals are special, ms. Utrecht/Nias/Nijmegen.

Vergnaud, J.-R. et M.-L. Zubizaretta (1992). The definite determiner and the inalienable construction in French and English, Linguistic Inquiry 23: 595652.

Zamparelli, R. (2002). Definite and bare kind-denoting noun phrases, in: C. Beyssade et al. (eds.) Romance languages and linguistic theory 2000, Amsterdam: John Benjamins, 305-342. 